\title{
Expression of thrombospondin-1 and its receptor CD36 in human osteoarthritic cartilage
}

\author{
David Pfander, Thorsten Cramer, Dieter Deuerling, Gerd Weseloh, Bernd Swoboda
}

\begin{abstract}
Objective-Thrombospondin-1 (TSP-1), a trimeric glycoprotein, is involved in cellmatrix interactions of various tissues, particularly in cartilage. Biochemical analyses show expression of TSP-1 in human cartilage, but its cellular source as well as the presence of its main surface receptors CD36 and CD51 in normal and osteoarthritic cartilage remain unknown. Therefore, to localise TSP-1 and its receptors immunohistochemistry and in situ hybridisation were used.
\end{abstract}

Methods-Radioactive in situ hybridisations with an RNA probe that encodes TSP-1 combined with immunostaining were carried out to investigate the expression patterns of TSP-1, CD36, and CD51 in seven normal and 23 osteoarthritic human cartilage samples.

Results-In normal cartilage TSP-1 was present mainly in the middle and upper deep zone. RNA expression was predominantly seen over chondrocytes of the middle zone. CD36 was found in chondrocytes of the superficial and upper middle zone. In mild and moderate osteoarthritic cartilage an increased number of TSP-1 expressing chondrocytes were seen and an increased pericellular staining close to the surface. In severe osteoarthritic cartilage a decrease in the number of TSP-1 synthesising chondrocytes and a strong reduction in matrix staining were observed. Most of these severe osteoarthritic samples showed a strongly enhanced number of CD36 positive chondrocytes. Conclusion-The cellular source of TSP-1 in normal cartilage is mainly mid-zone chondrocytes, which also express CD36. In early osteoarthritic cartilage lesions an increase of TSP-1 was seen, whereas reduced TSP-1 synthesis is paralleled by a strong decrease in TSP-1 protein staining in severe osteoarthritis. Furthermore, in severe osteoarthritic cartilage the number of CD36 immunostained chondrocytes is significantly increased.

(Ann Rheum Dis 2000;59:448-454)

Dr David Pfander, Division of Orthopaedic

Rheumatology, Department of Orthopaedic Surgery im Waldkrankenhaus St Marien, University of

Erlangen-Nuernberg,

Rathsbergerstr 57, D-91054

Erlangen, Germany

Email:

DPfander@t-online.de

Accepted for publication 8 December 1999 (mainly aggrecan) and small proteoglycans, hyaluronic acid, cations, and water. ${ }^{2}{ }^{3}$ Furthermore, different minor components, such as
Articular cartilage is a complex tissue, composed of a highly organised extracellular matrix and only a small number of embedded consists of large type II collagen fibrils collagen types VI, XI, X, and non-collagenous proteins like COMP, CMP, fibronectin, $58 \mathrm{kDa}$ protein, tenascin, $32 \mathrm{kDa}$ protein, and others, are present. ${ }^{4-8}$ The chondrocytes are responsible for the integrity of this highly organised matrix, by maintaining a balance between the synthesis and degradation of the cartilage matrix. TSP-1 is a member of the thrombospondin family. TSP-1 and TSP-2 have many structural similarities and should be distinguished from TSP-3, TSP-4, and TSP-5 (COMP), which share homologies with TSP-1 and TSP-2 only in the C terminal domain. ${ }^{9}$ TSP-1 is a trimeric glycoprotein with a molecular weight of $420 \mathrm{kDa}$. It consists of six different domains which are the $\mathrm{N}$ terminal domain, the procollagen homology domain, three type I (properdin-like) repeats, three type II (epidermal growth factor-like) repeats, seven type III (RGD sequence) repeats, and the C terminal domain. ${ }^{10}$ TSP- 1 is a multifunctional protein which mediates different cell-matrix interactions. Further, a recent study showed TSP-1 to be a major activator of transforming growth factor $\beta$ in vivo. ${ }^{11}$ Two main receptors of TSP-1 are known - the classical CD36 receptor, binding to type I repeats of TSP-1, and the CD51 receptor ( $\alpha_{v} \beta_{3}$ integrin), which binds to TSP-1 through RGD sequences of the type III repeats. ${ }^{12}$ TSP-1 has been shown to be present in human cartilage..$^{13}$ The cellular source, changes in synthesis pattern, and the distribution of TSP-1 and its receptors in osteoarthritic cartilage are unknown. Therefore, we investigated human normal and osteoarthritic cartilage for the expression of TSP-1, CD36, and CD51 and their correlation with the destruction of osteoarthritic cartilage.

\section{Materials and methods}

PATIENTS AND SAMPLES

The cartilage/bone samples were obtained from 22 patients who had been admitted to hospital in the Division of Orthopaedic Rheumatology, University Erlangen-Nürnberg, Germany. The clinical data obtained included age, sex, exploration, physical examination, haemanalysis (complete blood count, rheumatoid factors, erythrocyte sedimentation rate, serum electrophoresis, $\mathrm{C}$ reactive protein, and other serum diagnostics), and $x$ ray findings of the respective knee joints. These data were carefully reviewed to exclude any forms of secondary osteoarthritis (OA) and rheumatoid arthritis. Twenty three osteoarthritic human cartilage samples were obtained from 15 donors (nine female, six male, aged 59-79 years) undergoing total knee replacement. Seven human normal cartilage samples were 
Table 1 Results of immunostaining of thrombospondin-1 (TSP-1) in different matrix locations

\begin{tabular}{|c|c|c|c|c|c|c|c|c|c|c|c|c|c|c|}
\hline & \multicolumn{4}{|c|}{ Normal cartilage $(n=7)$} & \multicolumn{4}{|c|}{ Mild $O A(n=7)$} & \multicolumn{3}{|c|}{ Moderate $O A(n=7)$} & \multicolumn{3}{|c|}{ Severe $O A(n=9)$} \\
\hline & $S Z$ & $M Z$ & $D Z$ & $C C$ & $S Z$ & $M Z$ & $D Z$ & $C C$ & $M Z$ & $D Z$ & $C C$ & $M Z$ & $D Z$ & $C C$ \\
\hline $\begin{array}{l}\text { TSP-1 protein } \\
\text { interterritorial }\end{array}$ & $-/+$ & $+/++$ & + & - & + & + & + & - & + & + & - & + & - & - \\
\hline $\begin{array}{l}\text { TSP-1 protein } \\
\text { pericellular }\end{array}$ & - & ++ & - & - & - & ++ & - & - & +++ & + & - & + & + & - \\
\hline $\begin{array}{l}\text { TSP-1 RNA expressing } \\
\text { chondrocytes }(\%)\end{array}$ & $\begin{array}{l}5.6 \\
(2.6)\end{array}$ & $\begin{array}{l}13.1 \\
(4.7)\end{array}$ & $\begin{array}{l}4.9 \\
(3.0)\end{array}$ & 0.0 & $\begin{array}{l}4.8 \\
(1.1)\end{array}$ & $\begin{array}{l}14.8 \\
(8.2)\end{array}$ & $\begin{array}{l}4.0 \\
(2.8)\end{array}$ & 0.0 & $\begin{array}{l}28.5 \\
(8.8)^{\star}\end{array}$ & $\begin{array}{l}5.7 \\
(2.7)\end{array}$ & $\begin{array}{l}1.3 \\
(1.6)\end{array}$ & $\begin{array}{l}10.5 \\
(10.3)\end{array}$ & $\begin{array}{l}5.0 \\
(1.7)\end{array}$ & 0.0 \\
\hline $\begin{array}{l}\text { CD36 positive } \\
\text { chondrocytes (\%) }\end{array}$ & $\begin{array}{l}38.0 \\
(23.4)\end{array}$ & $\begin{array}{l}20.2 \\
(13.2)\end{array}$ & $\begin{array}{l}6.4 \\
(3.5)\end{array}$ & $\begin{array}{l}0.86 \\
(1.6)\end{array}$ & $\begin{array}{l}54.0 \\
(26.4)\end{array}$ & $\begin{array}{l}26.5 \\
(24.5)\end{array}$ & $\begin{array}{l}5.0 \\
(5.45)\end{array}$ & $\begin{array}{l}1.75 \\
(1.6)\end{array}$ & $\begin{array}{l}50.9 \\
(14.8)^{\star}\end{array}$ & $\begin{array}{l}36.3 \\
(26.4)^{\star}\end{array}$ & $\begin{array}{l}2.8 \\
(1.8)\end{array}$ & $\begin{array}{l}80.0 \\
(17.5)^{\star}\end{array}$ & $\begin{array}{l}61.4 \\
(35.5)^{\star}\end{array}$ & $\begin{array}{l}4.6 \\
(2.8)^{\star}\end{array}$ \\
\hline
\end{tabular}

obtained from four patients who underwent amputation.

TISSUE PREPARATION

The localisation of the excised samples was carefully recorded by video prints. In seven donors with macroscopical OA, two samples were obtained from the central weight bearing areas of the medial and lateral femoral condyles, and in eight cases the cartilage samples were obtained only from central areas of the lateral femoral condyle, because of a total loss of the medial compartment cartilage. The normal cartilage samples were recovered from macroscopically normal femoral condyles without any evidence of OA. The specimens were immediately fixed in $4 \%$ paraformaldehyde in phosphate buffered saline (PBS), decalcified in diethyl pyrocarbonate treated 0.2 $M$ EDTA, embedded in paraffin wax, and then cut into $6 \mu \mathrm{m}$ thick sections. Serial sections were stained with safranin $\mathrm{O}$.

HISTOLOGICAL-HISTOCHEMICAL GRADING

Safranin O stained sections of normal and osteoarthritic cartilage were graded routinely according to Mankin et al, by two different observers. ${ }^{15}$ Additionally, the cartilage samples were classified as normal or mild, moderate, and severe OA as follows: Mankin score $0-1=$ normal cartilage (seven samples); $2-5=$ mild osteoarthritic cartilage (seven samples); 6-9 = moderate osteoarthritic cartilage (seven samples); $\geqslant 10=$ severe osteoarthritic cartilage (nine samples).

\section{IMMUNOHISTOCHEMISTRY}

After deparaffinisation, the sections were incubated with $2 \mathrm{mg} / \mathrm{ml}$ hyaluronidase (Merck, Darmstadt, Germany) in PBS pH 5.5 for 15 minutes, followed by digestion with $1 \mathrm{mg} / \mathrm{ml}$ pronase for 30 minutes (Boehringer, Mannheim, Germany) in PBS pH 7.5. Non-specific binding of the antibodies was blocked by incubation with $5 \%$ bovine serum albumin in PBS. Each step was followed by extensive washing in PBS, then sections were incubated overnight at $4^{\circ} \mathrm{C}$, with a human TSP-1-specific monoclonal antibody diluted 1:20. Adjacent sections were incubated, without a digestive pretreatment, with a human CD36-specific monoclonal antibody, diluted 1:250, and a human CD51specific monoclonal antibody diluted between $1: 1000$ and $1: 100$ and various pretreatments were used-without digestion, digestion with pronase, protease-k, pronase and hyaluronidase, trypsin. Negative control cartilage sections were incubated with mouse control antibodies isotypes $\operatorname{IgG} 1$ and $\operatorname{IgM}$ as well as ascites fluid (NS-1). Further, human pancreas cancer and skin served as positive control. After incubation with the first antibody each step was followed by extensive washing in Tris buffered saline. Primary antibodies were then followed by incubation with a biotinylated antimouse IgG from rabbits diluted 1:200 for TSP-1 and 1:500 for CD36 and CD51. A complex of streptavidin and biotin labelled with alkaline phosphatase was then added according to the protocol of the manufacturer (Dako, Hamburg, Germany). Finally, the sections were coloured with Fast Red (Sigma, Munich, Germany).

\section{ANTIBODIES}

The following antibodies were used: monoclonal mouse antibody (IgG1) against human TSP-1 (Oncogene Science Inc, Cambridge, USA); monoclonal mouse antibody (IgM) against human CD36 (Chemicon International Inc, Temecula, USA); monoclonal antibody (IgG1) against human CD51 (Chemicon International Inc, Temecula, USA); mouse control antibodies, isotypes IgG1 and IgM (Dianova, Hamburg, Germany); control mouse ascites fluid (NS-1) (Sigma Biosciences, St Louis, USA); polyclonal biotin labelled antibody against mouse IgG (Dianova, Hamburg, Germany).

PREPARATION AND LABELLING OF PROBES

For the preparation of RNA probes the $1.25 \mathrm{~kb}$ EcoRI fragment of the human TSP-1 cDNA (American Type Culture Collection, ATCC No 61811, Manassas, USA) was subcloned into the vector pGEM2 (Promega Biotech, Heidelberg, Germany) at the appropriate restriction sites. After linearisation of the plasmid with either PvuII or BamHI restriction endonuclease, T7 or SP6 RNA polymerase (BRL Gibco, Eggenstein, Germany), respectively, were used to obtain run off transcripts of either the antisense (complementary to mRNA) or sense (anticomplementary, negative control) strands. Transcription and labelling were performed with $60 \mu \mathrm{Ci}$ of $\left[{ }^{35} \mathrm{~S}\right]$ uridine 5 -( $\alpha$-thio) triphosphate $1250 \mathrm{Ci} / \mathrm{mmol}(\mathrm{New}$ England Nuclear, Dreieich, Germany). To increase the penetration into tissue the size of the ${ }^{35} \mathrm{~S}$ labelled RNA probes was adjusted to 150-250 base length by controlled alkaline hydrolysis. The specific activity routinely ob- 

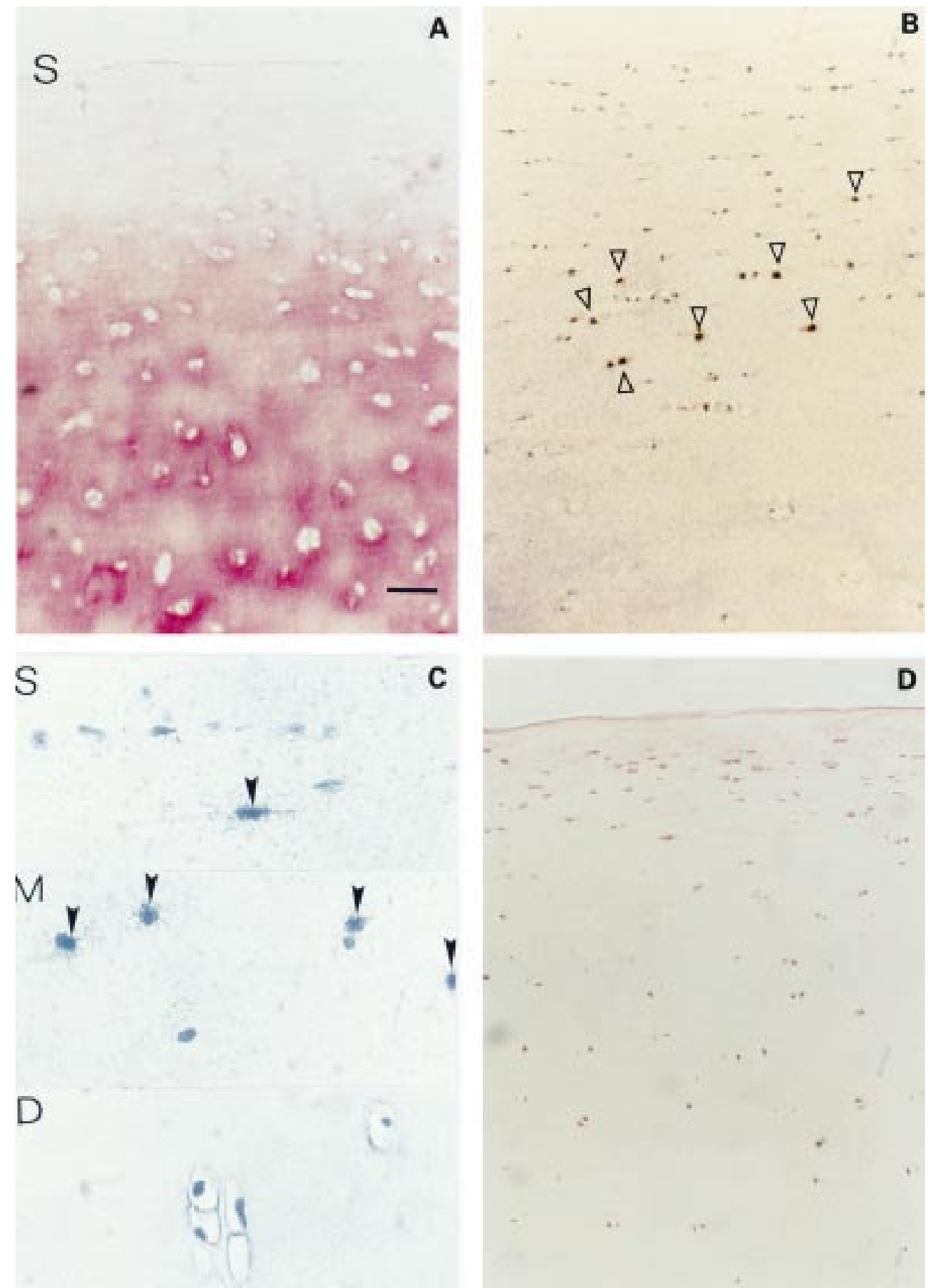

D

Figure 1 (A) Normal cartilage (three of seven samples, Mankin 1 and 0). Immunohistochemical staining of TSP-1 in normal human cartilage without TSP-1 staining in the superficial zone ( $S$ indicates cartilage surface). (B) In situ hybridisation of TSP-1 shows strong expression mainly in middle zone chondrocytes (open arrowheads). (C) High power magnification of typical zonal areas of the superficial $(S)$, middle $(M)$ and the deep (D) zone with positive TSP-1 RNA signals over chondrocytes of the superficial and middle zones (closed arrowheads). (D) Typical distribution of CD36 immunostained chondrocytes in normal cartilage. Bar represents $115 \mu \mathrm{m}$ in figs $A, B$, and $D$ and $30 \mu \mathrm{m}$ in fig $C$.

tained was $1.2-1.4 \times 10^{9} \mathrm{cpm} / \mu \mathrm{g}$ RNA. $5 \times 10^{5}$ cpm were applied to each section.

IN SITU HYBRIDISATION AND AUTORADIOGRAPHY Pre-hybridisation, hybridisation, washing procedures, and RNase digestion of mismatched sequences as well as autoradiography were performed as described by Milani et $a l .{ }^{16}{ }^{17}$ In brief, tissue sections were deparaffinised in xylene and rehydrated through graded ethanol, treated with $0.2 \mathrm{M} \mathrm{HCl}$, digested with pronase, fixed in $4 \%$ paraformaldehyde/PBS, acetylated, rinsed in PBS, dehydrated in graded ethanols, and air dried. Sections were hybridised at $52^{\circ} \mathrm{C}$ for 18 hours using $5 \times 10^{5} \mathrm{cpm}$ of ${ }^{35} \mathrm{~S}$ labelled RNA probe, washed for five hours at $52^{\circ} \mathrm{C}$ in modified hybridisation buffer, subjected to a brief RNase A digestion, washed briefly, dehydrated in graded ethanols, air dried, and dipped into Amersham's LM1 nuclear emul- 

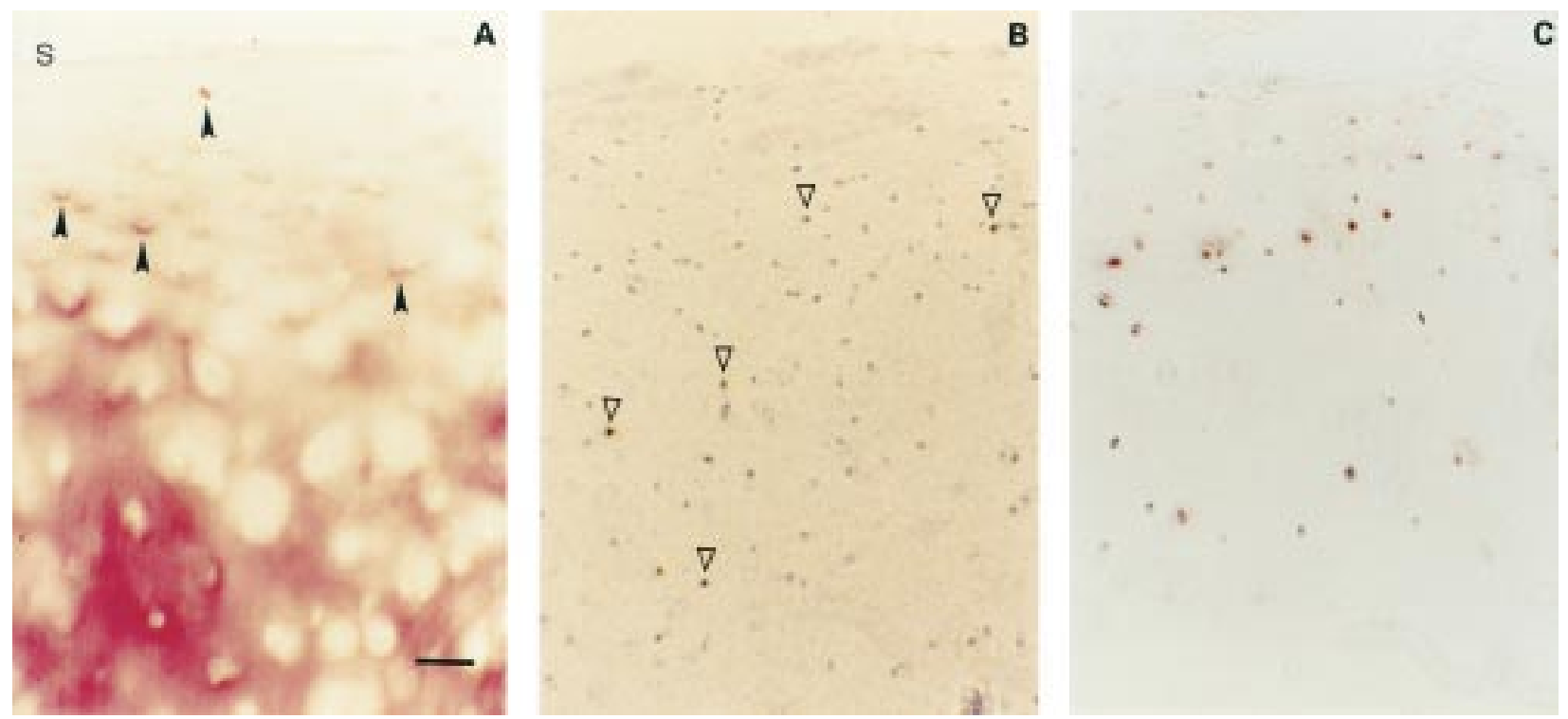

Figure 2 (A) Mild OA cartilage (one of seven samples, Mankin 4). Immunohistochemical staining of TSP-1 in mild OA cartilage showing chondrocytes with pericellular TSP-1 staining in the upper middle zone (closed arrowheads) and a predominantly interterritorial staining in the deep zone (s indicates cartilage surface). (B) In situ hybridisation of TSP-1 shows expression of middle and deep zone chondrocytes (open arrowheads). (C) CD36 positive chondrocytes are present in the middle and upper deep zones. Bar represents $125 \mu \mathrm{m}$ in figs $A, B$, and $C$.

sion (Amersham, Braunschweig, Germany). After exposure for 15 days at $4^{\circ} \mathrm{C}$, slides were developed in Kodak DI9 developer (Kodak, Hemel, Hempstead, UK) for three minutes, rinsed in $1 \%$ acetic acid and fixed in Kodak fixer for three minutes. After extensive washing, the slides were finally counterstained in haematoxylin/eosin and mounted in corbitt balsam. All sections from normal and osteoarthritic cartilage were processed in parallel using the same batches of probes and reagents. Hybridisation of tissues pretreated with micrococcus nuclease verified that cellular RNA was the target of hybridisation.

\section{MICROSCOPY AND STATISTICS}

Two adjacent slides of each immunohistochemical TSP-1, CD36, and CD51 sample as well as one of the sections of antisense and sense in situ hybridisation for TSP-1 were microscopically viewed and assessed by two independent observers. The percentage of positive chondrocytes (CD36 stained chondrocytes; chondrocytes with positive signals for TSP-1 RNA $\geqslant 15$ grains) was determined by counting 50 chondrocytes in each cartilage zone under a high power field with a magnification of $\times 312$. Means of the percentage of CD36 positive chondrocytes of two sections were calculated. The matrix deposition of TSP-1 was determined for all zones and two matrix localisations (interterritorial, pericellular) by the following system: $-=$ absent; $+=$ weak; $++=$ moderate $+++=$ strong; $++++=$ very strong. For statistical analyses Student's $t$ tests were performed, with the software program SPSS.

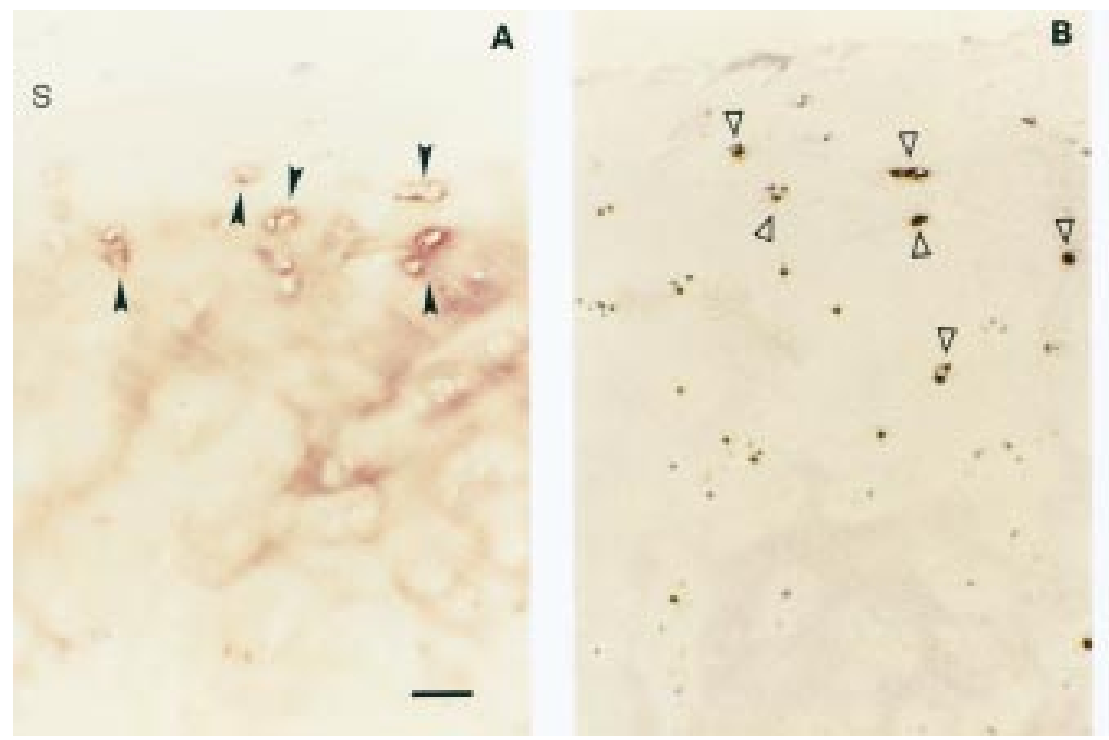

Figure 3 (A) Moderate OA cartilage (one of seven samples, Mankin 7). TSP-1 protein in moderate OA cartilage is present in the upper regions with a pericellular distribution, whereas in the deeper regions a slight interterritorial staining persists (s indicates cartilage surface). (B) Strong TSP-1 expression of the pericellularly stained chondrocytes was found by in situ hybridisation. (C) CD36 positive chondrocytes in co-localisation with TSP-1 expressing chondrocytes. Bar represents $125 \mu \mathrm{m}$ in figs $A, B$, and $C$. 


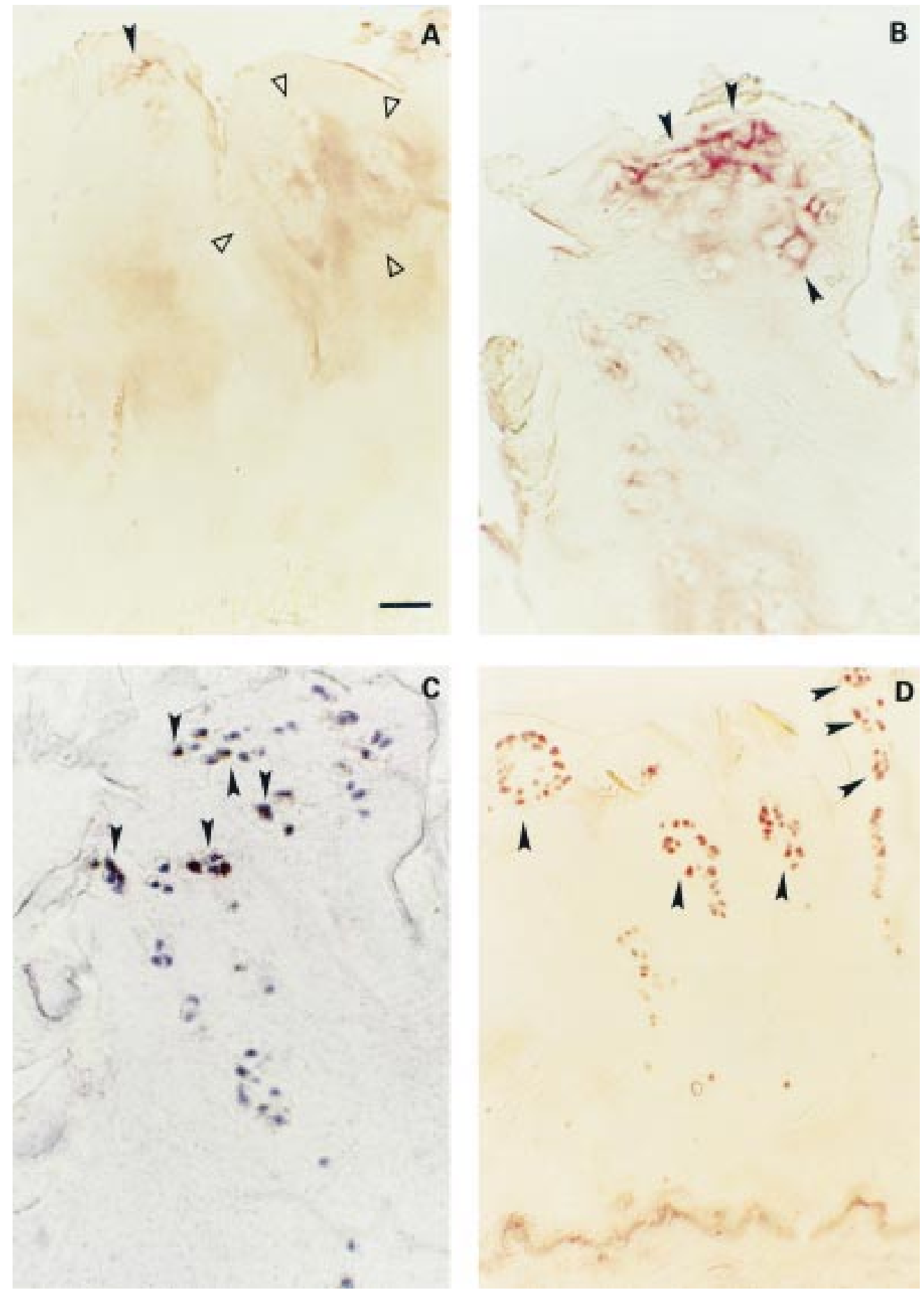

Figure 4 (A) Severe OA cartilage (two of nine samples, Mankin 13 and 14). Weak TSP-1 staining in the pericellular matrix of clustered chondrocytes (closed arrowhead) and a weak staining territorial and interterritorial on the right side (area between open arrowheads). (B) Magnification of a large chondrocyte cluster with a pericellular TSP-1 staining (closed arrowheads). (C) Adjacent slide with clustered chondrocytes showing TSP-1 expression (closed arrowheads). (D) Strong CD-36 protein expression of nearly $90 \%$ of the remaining clustered chondrocytes (closed arrowheads). Bar represents $125 \mu \mathrm{m}$ in figs $A$ and $D$, and $50 \mu \mathrm{m}$ in $B$ and $C$.

\section{Results}

Table 1 shows the results obtained.

TSP-1 and its receptor CD36 were found in normal and OA human cartilage. CD51, however, could not be detected in any of the cartilage samples.

In normal cartilage TSP-1 protein was present in the pericellular and interterritorial cartilage matrix of the middle and upper deep zones, whereas only weak or absent matrix staining was found in the superficial zone (fig 1A). TSP-1 RNA could be detected mainly in chondrocytes of the middle zone, whereas mRNA expression was less intense in the superficial and deep zones (figs $1 \mathrm{~B}$ and 1C). CD36 immunostained chondrocytes were found mainly in the superficial and middle zones (fig 1D). However, in the deep zone as well as the calcified cartilage only a small number of chondrocytes showed CD36. A 


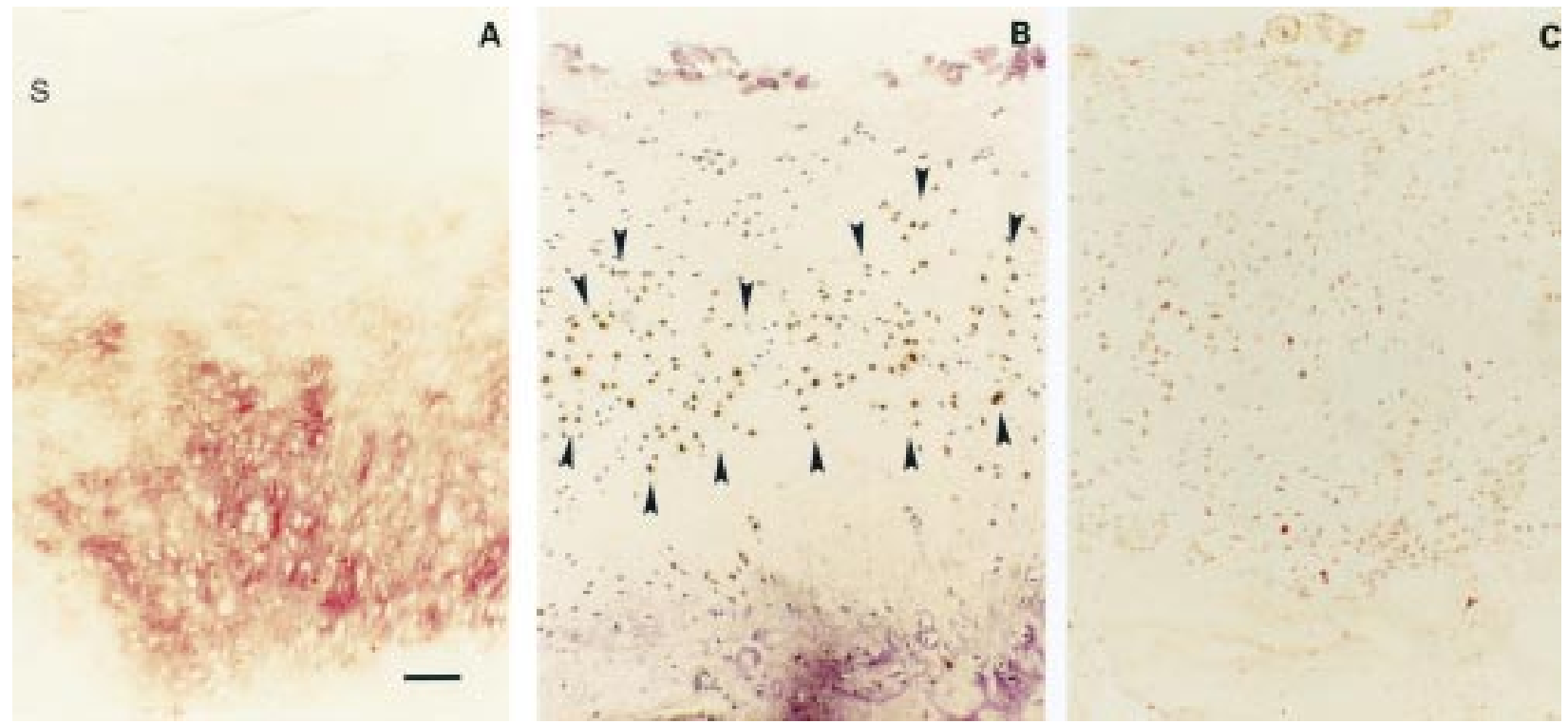

Figure 5 (A) Osteophytes. Strong immunohistochemical TSP-1 staining in osteophytes (s indicates cartilage surface). (B) Paralleled by a strong TSP-1 expression by in situ hybridisation (area between closed arrowheads). (C) Most of the chondrocytes are CD36 positive. Bar represents $125 \mu \mathrm{m}$ in figs $A, B$, and $C$.

large number of CD36 positive chondrocytes were found in all cartilage zones for only one of seven cartilage samples.

In mild OA cartilage an increase of TSP-1 protein mainly pericellularly localised and an enhanced number of chondrocytes showing TSP-1 expression was found (fig 2A). The main proportion of chondrocytes displaying positive TSP-1 RNA signals was located in the middle zone of the cartilage (fig 2B). Additionally, CD36 expressing chondrocytes were found in the superficial and middle zones but also distributed throughout the whole cartilage without any specific distribution pattern (fig 2C).

Moderate OA cartilage was characterised by an increased pericellular matrix staining combined with a significantly enhanced number of OA chondrocytes which show TSP-1 signals close to the cartilage surface (figs $3 \mathrm{~A}$ and $\mathrm{B}$ ). This was paralleled in a few cases by a decreased interterritorial matrix staining for TSP-1 in the deep zone. A significantly increased percentage of CD36 immunostained chondrocytes was either co-localised in the same areas as TSP-1 staining or, additionally, in a small number of chondrocytes in the lower deep zone and below in the calcified cartilage (fig 3C).

Severe OA cartilage samples showed an overall reduction in TSP-1 protein (fig 4A) and TSP-1 RNA content. In a small number of samples a moderate pericellular staining around chondrocyte clusters showing RNA expression was found (figs $4 \mathrm{~B}$ and $\mathrm{C}$ ). In severe OA samples with weak or no RNA and protein expression of TSP-1, we found a significant increase in the number of CD36 stained chondrocytes, compared with normal, mild, and moderate OA cartilage - up to a maximum of $94 \%$ positive chondrocytes in one of the samples (fig 4D).

Furthermore, osteophytes showed areas of strong and patchy TSP-1 staining paralleled by an increase in TSP-1 synthesis (figs $5 \mathrm{~A}$ and B). Corresponding areas with $\mathrm{CD} 36$ positive chondrocytes were observed (fig 5C).

\section{Discussion}

TSP-1 is known to be present in cartilage as described by Miller and DiCesare. ${ }^{13}{ }^{14}$ TSP-1 mediates signals by interacting between the cell surface and extracellular matrix components and, therefore, it may be an important regulatory factor in the cartilage metabolism. ${ }^{4910}$ In fact, different studies described TSP-1 expression and its potential role in the development of embryonic and epiphysial cartilage.$^{18}{ }^{19}$ Interestingly, TSP-1 seems to be the major activator of transforming growth factor $\beta$ and has high affinity binding regions to other growth factors, such as hepatocyte growth factor, which is present in normal and OA cartilage. ${ }^{11} 2021$

In our study the RNA and protein expression of TSP-1 and the presence of its receptor CD36 in normal and OA human cartilage were investigated. Miller and McDevitt proposed that TSP-1 binds to chondrocyte surface receptors by an RGD dependent mechanism. ${ }^{22}$ Since CD51 is known to bind TSP-1 through an RGD dependent mechanism, CD51 might be a potential candidate for a TSP-1 surface receptor on chondrocytes, but we could not detect any specific signals for CD51 in cartilage.

TSP-1 RNA was seen mainly over mid-zone chondrocytes in normal cartilage, whereas the immunohistochemical TSP-1 staining included also the deep zone. In mild OA cartilage a slight increase in TSP-1 RNA expression by middle zone chondrocytes was found. The decreased interterritorial and increased pericellular immunostaining suggest an enhanced digestive degradation of TSP-1 at this stage of disease. OA cartilage with moderate changes showed an interterritorial reduction in TSP-1 protein staining. Furthermore, chondrocytes of 
the upper OA cartilage showed strong RNA signals, which were paralleled by a pericellular TSP-1 deposition. At this stage the superficial zone is already lost. So it is likely, that the TSP-1 expressing chondrocytes are former mid-zone cells. In addition, in moderate OA cartilage CD-36 protein expression was significantly increased, predominantly in the upper cartilage. Severe OA cartilage showed a major decrease in TSP-1 protein, and, additionally, displayed a significant reduction in TSP-1 RNA expression compared with cartilage showing a moderate destruction. No significant differences in TSP-1 RNA expression were found between severe OA cartilage and mild OA or normal cartilage. Surprisingly, in most of these severe OA samples a strong increase in CD36 stained chondrocytes could be seen.

These observations suggest that TSP-1 is predominantly expressed in middle zone chondrocytes in normal and $\mathrm{OA}$ cartilage showing moderate changes. Furthermore, in these OA stages the CD36 receptor is likely to mediate some of the chondrocytethrombospondin interactions.

In contrast with cartilage showing mild and moderate changes, in severe OA samples reduced TSP-1 RNA levels and a greatly reduced matrix staining were paralleled by a strong enhancement of CD36 positive chondrocytes - up to $94 \%$. The possibility that an increased concentration of interleukin 1 in OA synovial fluid may reduce the TSP-1 expression in these stages cannot be excluded, as described for cultured rabbit chondrocytes. ${ }^{23}$ On the other hand, the increased CD36 expression of OA chondrocytes may be interpreted as a vain effort to contact TSP-1 in the extracellular matrix, which is lost in these late stages of OA and may be a part of the general metabolic activation of $\mathrm{OA}$ chondrocytes. A hypothesis can be proposed that TSP-1 may have functions in the deposition and activation of potential anabolic growth factors in articular cartilage, such as transforming growth factor $\beta 1$ or human growth factor. So it is likely that the absence of TSP-1 protein in severe OA cartilage may reduce the proportion of available growth factors and thus their biological activity.

Future work should explore these hypotheses, including the role of TSP-1 in activating and storing growth factors, as described for transforming growth factor $\beta 1$, which is known to be one of the most potent anabolic growth factors for cultured chondrocytes and to be upregulated in degenerative OA cartilage. ${ }^{24}$
1 Hardingham TE. Proteoglycans. Their structure interactions and molecular organization in cartilage. Biochem Soc Trans 1981;9:489-97.

2 Mayne R. Cartilage collagens. What is their function, and are they involved in articular disease? Arthritis Rheum 1989;32:241-6.

3 Urban JPG. The chondrocyte: a cell under pressure. Br J Rheumatol 1994;33:901-8.

4 Heinegard D, Oldberg A. Structure and biology of cartilage and bone matrix noncollagenous macromolecules. FASEB J 1989;3:2042-51.

5 Lohmander LS. Articular cartilage and osteoarthrosis. The role of molecular markers to monitor breakdown, repair role of molecular markers to monito
and disease. J Anat 1994;184:477-92.

6 Aigner T, Bertling W, Stöss H, Weseloh G, von der Mark K. Independent expression of fibril-forming collagens I, II and III in chondrocytes of human osteoarthritic cartilage. J Clin Invest 1993;91:829-37.

7 Swoboda B, Pullig O, Kirsch T, Kladny B, Steinhäuser B, Weseloh G. Increased content of type-VI collagen epitopes in human osteoarthritic cartilage: quantitation by inhibition ELISA. J Orthop Res 1998;16:96-9.

8 Pfander D, Rahmanzadeh R, Scheller EE. Presence and distribution of collagen II, collagen I, fibronectin and tenascin in rabbit normal and osteoarthritic cartilage. J Rheumatol 1999;26:386-94.

9 Bornstein P, Sage EH. Thrombospondins. Methods Enzymol 1994;245:82-5.

10 Lawler J, Hynes RO. The structure of human thrombospondin an adhesive glycoprotein with multiple calcium-binding sites and homologies with several different proteins. J Cell Biol 1986; 103:1635-48.

11 Crawford SE, Stelmach V, Murphy-Ullrich JE, Ribero SMF, Lawler J, Hynes RO, et al. Thrombospondin-1 is a major activator of TGF- $\beta 1$ in vivo. Cell 1998;93:1159-70.

12 Qian X, Tuszynski GP. Expression of thrombospondin-1 in cancer: a role in tumor progression. Proc Soc Exp Biol Med 1996;212:199-207.

13 Miller RR, McDevitt CA. Thrombospondin is present in articular cartilage and is synthesized by articular chondrocytes. Biochem Biophys Res Commun 1988;153:708-14.

14 DiCesare PE, Mörgelin M, Mann K, Paulsson M. Cartilage oligomeric matrix protein and thromospondin 1. Purification from articular cartilage, electron microscopic structure, and chondrocyte binding. Eur J Biochem 1994;223: 927-33.

15 Mankin H, Dorfman H, Lippiello L, Zarins A. Biochemical and metabolic abnormalities in articular cartilage from osteoarthritic human hips. II. Correlation of morphology with biochemical and metabolic data. J Bone Joint Surg Am 1971;53:523-37.

16 Milani S, Herbst H, Schuppan D, Hahn EG, Stein H. In situ hybridization for procollagen types I, III and IV mRNA in normal and fibrotic rat liver: evidence for predominant expression in nonparenchymal liver cells. Hepatology 1989;10:84-92.

17 Herbst H, Heinrichs O, Milani S, Schuppan D. Phenotype of procollagen-expressing cells in rat and human liver. Hisof procollagen-expressing cells in rat and

18 Tucker RP, Hagios T, Chiquet-Ehrismann R, Lawler J. In situ localization of thrombospondin-1 and thrombospondin-3 transcripts in the avian embryo. Dev Dyn 1997;208:326-37.

19 Iruela-Arispe ML, Liska DJ, Sage EH, Bornstein P. Differential expression of thrombospondin 1,2 and 3 during murine development. Dev Dyn 1993;197:40-56.

20 Lamszus K, Joseph A, Jin L, Yao Y, Chowdhury S, Fuchs A, et al. Scatter factor bind to thrombospondin and other extracellular matrix proteins. Am J Pathol 1996;149:80519.

21 Pfander D, Cramer T, Weseloh G, Pullig O, Schuppan D, Bauer M, et al. Hepatocte growth factor in human osteoar-
thritic cartilage. Osteoarthritis Cartilage 1999;7:548-59.

22 Miller RR, McDevitt CA. Thrombospondin 1 binds to the surface of bovine articular cartilage by a linear RGDsurface of bovine articular cartilage by a linear R
dependent mechanism. FEBS Lett 1995;363:214-16.

23 Lyons-Giordano B, Kefalides NA, Brinker JM, Pratta MA, Amer EC. The effects of interleukin-1 on the expression of thrombospondin and fibronectin by rabbit articular chondrocytes. Exp Cell Res 1991;195:462-7.

24 Moos V, Fickert S, Müller B, Weber U, Sieper J. Immunohistological analysis of cytokine expression in human osteoarthritic and healthy cartilage. J Rheumatol $1999 ; 26: 870-9$. 